\title{
Influence of Beta Vulgaris Supplementation on the Level of Oxidative DNA Damage/Oxidative Stress in Head and Neck Cancer Patients Undergoing Radiotherapy
}

Krzysztof Roszkowski*

Department of Radiotherapy, Oncology Center Bydgoszcz, Poland

\begin{abstract}
Because of the many controversies concerning the consumption of antioxidants during the treatment of cancer herein we decided to ascertain whether the supplementation of Beta vulgaris (strong antioxidant) in irradiated head and neck cancer patients would influence parameters which describe oxidative stress/DNA damage and the clinical effects of therapy.

Forty one patients with head and neck cancer (T3-4 N1 M0) were divided into two subgroups: I/supplementation chips from beetroot $(n=19)$ and II/control group $(n=22)$. All the patients were eligible for radiotherapy; acute reactions were measured using the Dische scale. Total survival times were assessed together with oxidative DNA damage on the level of the whole organism and whether the biomarkers of the damage such as 8-oxo-dG and its modified base (8-oxo-Gua) were present in urine and DNA.

Results of the present work suggest that with irradiated patients supplementation of Beta vulgaris does not worsen survival times, intensification of acute radiation reactions is reduced, and the level markers of oxidative stress/DNA damage are also not influenced.

Results also suggest that supplementation of Beta vulgaris in irradiated patients is the safe method for assisting therapy.
\end{abstract}

Keywords: Radiotherapy; Oxidatively damaged DNA; Head and neck cancer patients; Beta vulgaris supplementation

\section{Introduction}

Since antioxidants may reduce certain types of toxicity associated with conventional therapy many cancer patients take antioxidant vitamin supplements along with therapy [1] to enhance the benefits of treatment or to alleviate the side effects. However, some recently obtained data suggest that they may also interfere with the efficacy of the therapy [2-6].

Alternative to supplementation with high doses of antioxidant vitamins, certain kinds of food components, fruits and/or vegetables rich in antioxidant capabilities may be used. One such plant is beetroot (Beta vulgaris). Medicinally, beetroot is used as a popular folk remedy to stimulate the immune system and as a special diet in the treatment of cancer [7]. Several studies have demonstrated that beetroot is a good source of natural antioxidants $[8,9]$.

The interaction of ionizing irradiation (IR) with water is responsible for free radicals production including the highly reactive hydroxyl radical that can cause oxidatively damaged DNA [10]. Therefore, it is possible that oxidatively damaged DNA which arises as a result of radiotherapy may be involved in the therapeutic effect of the IR and may be involved in the side effects.

Antioxidants are compounds that can counteract free radicals and prevent them from causing tissue and organ damage [11-13]. Some data suggest antioxidants can ameliorate toxic side effects of therapy without affecting treatment efficacy, whereas other data suggest antioxidants interfere with radiotherapy [14-17] .

It may be supposed that controversies relating to the behavior of antioxidants in conventional anticancer therapy can result from individual differences of "oxidative status" in irradiated patients.
Therefore, for the first time, the broad spectrum of oxidative DNA damage biomarkers, urinary excretion of 8-oxodG (8-oxo-7, 8-dihydro2 '-deoxyguanosine), 8-oxoGua (8-oxo-7, 8-dihydroguanine) as well as the level of oxidative DNA damage in leukocytes, was analysed in head and neck cancer patients $(\mathrm{n}=41)$ undergoing fractionated radiotherapy with supplementation of strong antioxidant.

\section{Material and Methods}

Forty one patients with head and neck cancer (T3-4 N1 M0) were irradiated from September 2005 to May 2006.

In the presented study, patients were divided into two subgroups:

1. Supplemental chips from beetroot $(n=19)$

2. Control group $(\mathrm{n}=22)$

All the patients were eligible for radiotherapy. Patients were treated by radiotherapy with $6-\mathrm{MeV}$ photons for a total dose of $70 \mathrm{~Gy}$, given in fractions of 2 Gy per day, 24-h interval between 2 irradiation exposures, 5 days per week. The Planning Target Volume (PTV) encompassed in all patients the primary tumor site and a margin of approximately 1.5 $\mathrm{cm}$.

*Corresponding author: Krzysztof Roszkowski, Department of Radiotherapy Oncology Center Bydgoszcz, Romanowskiej 2, 85-796 Bydgoszcz, Poland, E-mail: roszkowskik@co.bydgoszcz.pl

Received May 07, 2012; Accepted August 27, 2012; Published August 31, 2012 Citation: Roszkowski K (2012) Influence of Beta Vulgaris Supplementation on the Level of Oxidative DNA Damage/Oxidative Stress in Head and Neck Cancer Patients Undergoing Radiotherapy. J Nucl Med Radiat Ther 3:139. doi:10.4172/2155-9619.1000139

Copyright: ( 2012 Roszkowski K. This is an open-access article distributed unde the terms of the Creative Commons Attribution License, which permits unrestricted use, distribution, and reproduction in any medium, provided the original author and source are credited. 
Citation: Roszkowski K (2012) Influence of Beta Vulgaris Supplementation on the Level of Oxidative DNA Damage/Oxidative Stress in Head and Neck Cancer Patients Undergoing Radiotherapy. J Nucl Med Radiat Ther 3:139. doi:10.4172/2155-9619.1000139

Daily supplementation was 20 grams (the equivalent of ca. $200 \mathrm{~g}$ of beetroot) chips of beetroot for the first week, and $10 \mathrm{~g}$ in the following weeks.

The control group was chosen in such a way that the following criteria matched the patient group: eating habits, age, body weight, sex and smoking status.

All the patients were eligible for radiotherapy. Acute reactions were measured using the Dische scale estimated $1 \mathrm{x}$ in the week. Total survival times in individual subgroup patients were estimated.

Spot urine samples and blood were collected before the treatment and supplementation (sample A), 7 days (B) and 14 days (C) after beginning the radiotherapy and 1 day after the last irradiation (D).

In the presented study, daily excretion of 8-oxoGua and 8-oxodG in urine and the level of 8-oxodG in leukocytes of peripheral blood of patients were analyzed.

\section{Isolation of leukocytes from venous blood}

Venous blood samples $(18 \mathrm{ml})$ were collected from the patients. The blood was carefully applied on top of Histopaque 1119 solution (Sigma-Aldrich Inc.; St.Louis, MO, USA) and leukocytes were isolated by centrifugation according to the procedure laid down by the manufacturer.

\section{DNA isolation and 8-oxodG determination in DNA isolates}

DNA from leukocytes was isolated using the method described earlier [18]. Determination of 8-oxodG by means of HPLC/EC technique was described previously $[18,19]$.

\section{Urine analysis}

Urine sample preparation, HPLC purification and GC/MS analysis were conducted as described earlier [18].

\section{Statistical analysis}

All results are expressed as means. The StatSoft, Inc. (2009) STATISTICA version 9.0. (lic. no: JXVP002E256522AR-E) was used for the statistical analysis. Student t-test (for variables with normal distribution - levels of oxidatively damaged DNA before and after RT) was carried out.

The association between the overall survival subgroup with supplementation of Beta vulgaris and control patients was estimated using the method of Kaplan and Meier and assessed using the log-rank test. Statistical significance was considered at $\mathrm{p}<0.05$. The study was approved by the medical ethics committee of The Collegium Medicum Nicolaus Copernicus University Bydgoszcz, Poland, No 462/2005 (in accordance with Good Clinical Practice, Warsaw 1998) and all the patients gave informed consent.

\section{Results}

The subgroup of patients on supplementation revealed slightly lower values of acute reactions in particular weeks of radiotherapy, assessed according to the Dische scale $(5,8,11,10,11,11,10$ points) as compared to the subgroup without supplementation $(4,9,12,12,14,12,13$ points) (Figure 1). The differences were not statistically significant.

The supplementation with Beta vulgaris during radiotherapy did not have any influence on the values of the urinary oxidative stress markers 8-oxo-Gua and 8-oxo-dG or on the amount of 8-oxo-dG in cellular DNA at particular time points of measurement, in the examined subgroups of patients (Figure 2).
The median total survival time in the subgroup of patients with supplementation was higher as compared to the control subgroup and amounted to 36.8 and 26.1 months, respectively (Figure 3).

\section{Discussion}

According to previous studies, blood antioxidant level in patients is very variable and may be dependent on both diet and on genetic factors $[20,21]$. The level of oxidative DNA damage is similarly variable $[22,23]$. Nevertheless, supplementation with beetroot chips in patients with cancer subjected to radiotherapy should alleviate the effects of oxidative shock, and thus decrease the level of side effects of the applied treatment. It should be underscored that the level of the modified base in urine, a general marker of oxidative shock, may be an indicator of oxidative DNA damage or DNA repair, taking into account a stable level of cellular DNA modifications [24]. Therefore, in the presented study, the urinary levels of 8-oxo-Gua and 8-oxo-dG, as well as 8-oxodG in DNA of peripheral blood leukocytes were determined in both subgroups of patients (those on supplementation with an antioxidant or without supplementation) at several time points of measurement. The results of the measurements are surprising (Figure 2). Only in the first two weeks of radiotherapy were the urinary 8-oxo-dG levels higher in patients on supplementation, with no differences in the urinary 8-oxoGua levels and lower values of 8-oxo-dG in cellular DNA during the whole treatment, as compared to the control group. Reduced activity of the main enzyme responsible for removal of 8-oxo-Gua from DNA should result in accumulation of cellular DNA damage, with increased urinary excretion of the studied analogues $[25,26]$.

The observed results in the group of subjects on supplementation show that it is possible that in some patients with high OGG1 activity a combination of increased OGG1 activity with antioxidant supplementation during treatment is connected with a decreased intensity of radiation reactions, and thus with a protective antioxidative activity of Beta vulgaris. The presented study may confirm this hypothesis.

A few serious studies have suggested that supplementation with antioxidants may reduce the effectiveness of anti neo plastic therapy $[6,14,27]$. The mechanism of these statements is based on a suggestion that antioxidants neutralize the destructive effects of reactive forms of oxygen on neoplastic cells, and therefore decrease the effects of radiotherapy [28].

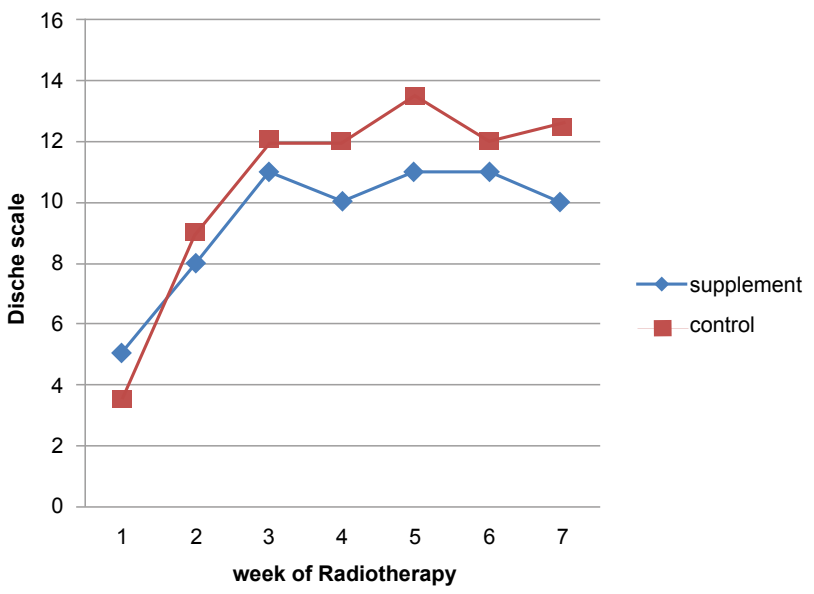

Figure 1: Values of reaction according to the Dische scale in particular weeks of radiotherapy in the group of patients on supplementation $(n=19)$ and in the control group $(n=22)$. 


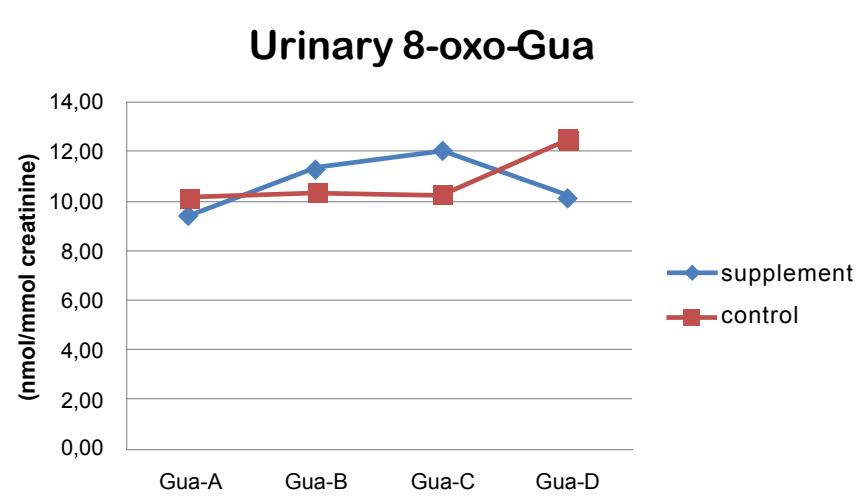

Urinary 8-oxo-dG

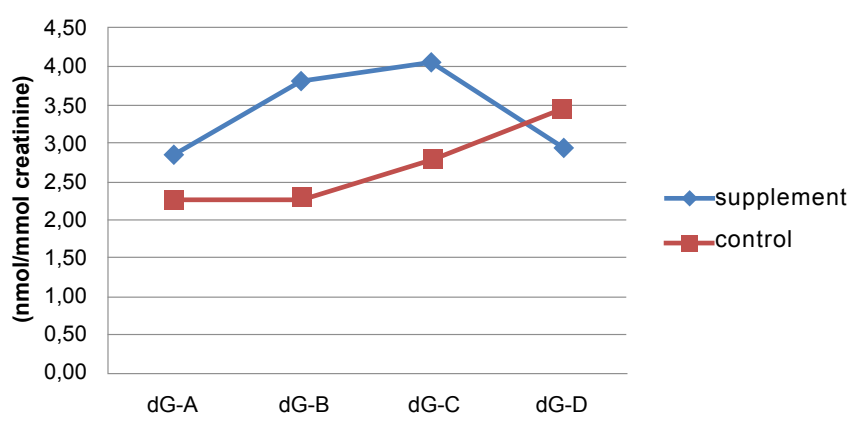

Leukocytes'8-oxo-dG/1066

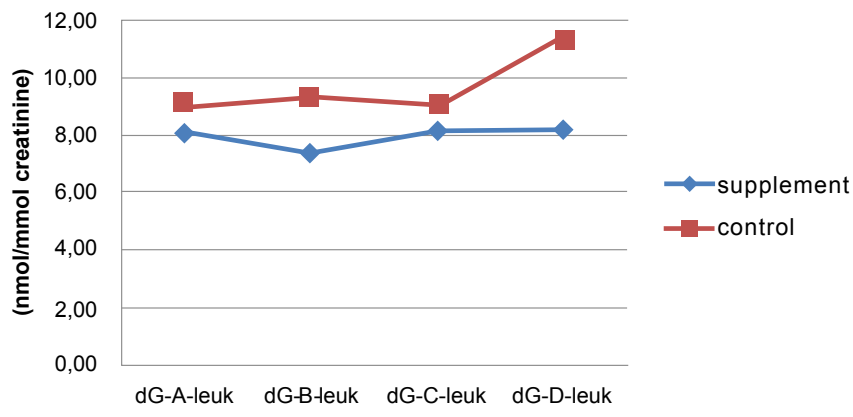

Figure 2: Values of the urinary oxidative stress markers 8-oxo-Gua and 8-oxo-dG and of the amount of 8-oxo-dG in cellular DNA at particular time points of measurement (A-before IR and supplementation; B-1 week IR; C-2 week IR; D- post IR) in the examined subgroups of patients.

The results presented here differ from these suggestions. As far as long-term results of treatment are concerned, a longer total survival time was observed in the subgroup of patients on supplementation (Figure 3). These differences may follow from a number of circumstances.

Apart from antioxidative activity, beetroots have antiviral and antibacterial properties as well; for instance they act as cyclooxygenase inhibitors $[29,30]$. In particular, one pigment in the betalain group, betanin, appears to be a potent anticancer compound. Beetroot extract, rich in betalain pigments, has demonstrated chemopreventive properties against both lung and skin cancers [31]. Studies with murine hepatoma cells showed that betanin may act as a quinine reductase inducer (a phase II enzyme important as a marker of the initiation stage of carcinogenesis) [32].

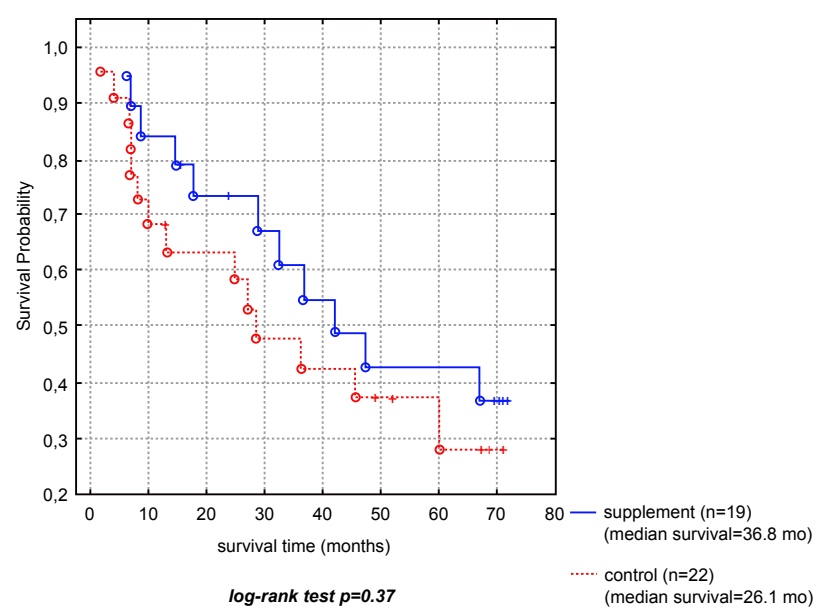

Figure 3: Kaplan-Meier curves of supplemental $(n=19)$ and control $(n=22)$ patients.

Another study [9] indicated that beetroot products inhibited neutrophil oxidative metabolism in obese individuals. Also observed were the pro-apoptotic effects of beetroot in an in vitro concentration culture of stimulated neutrophils.

All the measured parameters which describe oxidatively damaged DNA reflect the damage on the level of the whole body. The most plausible explanation of the described finding is IR-mediated inflammatory response. Many pro-inflammatory cytokines have been shown to be induced by IR and some of the cytokines can provoke the production of large amounts of reactive oxygen species (ROS), which is likely directly linked with increased urinary 8-oxo-dG. On the other hand these natural antioxidant products (in both the liquid and solid state) have antioxidant and anti inflammatory capacity, which could be an important adjunct in the treatment of cancer, and may also be used to fight cancer cells, so patients from this group have better chances of surviving longer.

Summing up, due to controversies with using antioxidants in patients treated with radiotherapy, we decided to ascertain whether the administration of Beta vulgaris to patients during radiotherapy influences the level of parameters which describe oxidative DNA damage and whether the supplementation influences treatment outcomes. The results suggest that supplementation with Beta vulgaris in radiated patients is a safe method supporting the therapy. Vegetables such as beetroot, rich in antioxidative compounds, may be an attractive alternative for 'pharmaceutical' vitamins, overdosing of which may produce adverse reactions. Such a supplementation offers not only a given chemical compound but also a wide spectrum of compounds with curative potential, and not fully understood action.

Definite confirmation of the presented results, being a part of the implemented project, requires recruitment of a much more numerous group of patients and a long follow-up, which would allow for correlating the results of the analyses with clinical effects. An attractive group, indicated in such studies, includes patients with malignancies, treated radically with a good prognosis.

\section{Acknowledgments}

I would like to thank Professor Ryszard Olinski, Department of Clinical Biochemistry, Collegium Medicum, Nicolaus Copernicus University, Bydgoszcz, 
Citation: Roszkowski K (2012) Influence of Beta Vulgaris Supplementation on the Level of Oxidative DNA Damage/Oxidative Stress in Head and Neck Cancer Patients Undergoing Radiotherapy. J Nucl Med Radiat Ther 3:139. doi:10.4172/2155-9619.1000139

$\mathrm{PL}$ for the inspiration to perform this work and his making possible laboratory investigations. I would like to acknowledge the contributions of Rafal Rozalski and Daniel Gackowski to this study.

\section{References}

1. Burstein HJ, Gelber S, Guadagnoli E and Weeks J (1999) Use of Alternative Medicine by Women With Early-Stage Breast Cancer. N Engl J Med 340: 17331739.

2. Ladas EJ, Jacobson JS, Kennedy DD, Teel K, Fleischauer A, et al. (2004) Antioxidants and Cancer Therapy: a Systematic Review. J Clin Oncol 22: 517528.

3. Ferreira PR, Fleck JF, Diehl A, Barletta D, Braga-Filho A, et al. (2004) Protective effect of alpha-tocopherol in head and neck cancer radiation-induced mucositis: a double-blind randomized trial. Head Neck 26: 313-321.

4. Bairati I, Meyer F, Ge'linas M, Fortin A, Nabid A, et al.(2005) A randomized trial of antioxidant vitamins to prevent second primary cancers in head and neck cancer patients. J Natl Cancer Inst 97: 481-488.

5. D'Andrea GM (2005) Use of Antioxidants During Chemotherapy and Radiotherapy Should Be Avoided. CA Cancer J Clin 55: 319-321.

6. Bairati I, Meyer F, Jobin E, Gélinas M, Fortin A, et al. (2006) Antioxidan vitamins supplementation and mortality: a randomized trial in head and neck cancer patients. Int J Cancer 119: 2221-2224.

7. Chevallier A (1996) The encyclopedia of medicinal plants. New York: DK Publishing Inc p.176.

8. Kapadia GJ, Azuine MA, Sridhar R, Okuda Y, Tsuruta A, et al. (2003) Chemoprevention of DMBA-Induced UV-B Promoted, NOR-1-Induced TPA Promoted Skin Carcinogenesis, and DEN-Induced Phenobarbital Promoted Liver Tumors in Mice by Extract of Beetroot. Pharmacol Res 47: 141-148.

9. Zielinska-Przyjemska M, Olejnik A, Dobrowolska-Zachwieja A, Grajek W (2009) In vitro Effects of Beetroot Juice and Chipson Oxidative Metabolism and Apoptosis in Neutrophils from Obese Individuals. Phytother Res 23: 49-55.

10. Barcellos-Hoff MH, Park C, Wright EG (2005) Radiation and the microenvironment - tumorigenesis and therapy. Nat Rev Cancer 5: 867-875.

11. Kikawa KD, Herrick JS, Tateo RE, Mouradian M, Tay JS, et al. (2010) Induced oxidative stress and cell death in the A549 lung adenocarcinoma cell line by ionizing radiation is enhanced by supplementation with docosahexaenoic acid. Nutr Cancer 62: 1017-1024.

12. Ratnam DV, Ankola DD, Bhardwaj V, Sahana DK, Kumar MN (2006) Role of antioxidants in prophylaxis and therapy: a pharmaceutical perspective. $J$ Control Release 20: 189-207.

13. Salganik RI (2001) The benefits and hazards of antioxidants: controlling apoptosis and other protective mechanisms in cancer patients and the human population. J Am Coll Nutr 20: 464S-472S

14. Ferreira PR, Fleck JF, Diehl A, Barletta D, Braga-Filho A, et al. (2004) Protective effect of alpha-tocopherol in head and neck cancer radiation-induced mucositis: a double-blind randomized trial. Head Neck 26: 313-321.

15. Sakhi AK, Bøhn SK, Smeland S, Thoresen M, Smedshaug GB, et al. (2010) Postradiotherapy plasma lutein, alpha-carotene, and beta-carotene are positively associated with survival in patients with head and neck squamous cell carcinoma. Nutr Cancer 62: 322-328.

16. Wasserman TH, Brizel DM, Henke M, Monnier A, Eschwege F, et al. (2005) Influence of intravenous amifostine on xerostomia, tumor control, and survival after radiotherapy for head-and-neck cancer: 2-year follow-up of a prospective, randomized, phase III trial. Int J Radiat Oncol Biol Phys 63: 985-990.

17. Buentzel J, Micke O, Adamietz IA, Monnier A, Glatzel M, et al. (2006) Intravenous amifostine during chemoradiotherapy for head-and-neck cancer: a randomized placebo-controlled phase III study. Int J Radiat Oncol Biol Phys 64: 684-691.

18. Siomek A, Gackowski D, Rozalski R, Dziaman T, Szpila A, et al. (2007) Higher leukocyte 8-oxo-7,8-dihydro-20-deoxyguanosine and lower plasma ascorbate in aging humans? Antioxid Redox Signal 9: 143-150.

19. Foksinski M, Bialkowski K, Skiba M, Ponikowska I, Szmurlo W, et al. (1999) Evaluation of 8-oxodeoxyguanosine, typical oxidative DNA damage, in lymphocytes of ozone-treated arteriosclerotic patients. Mutat Res 43: 23-27.
20. Cooke MS, Evans MD, Dove R, Rozalski R, Gackowski D, et al. (2005) DNA repair is responsible for the presence of oxidatively damaged DNA lesions in urine. Mutat Res 574: 58-66.

21. Roszkowski K, Jozwicki W, Blaszczyk P, Mucha-Malecka A, Siomek A (2011) Oxidative damage DNA: 8-oxoGua and 8-oxodG as molecular markers of Cancer. Med Sci Monit 17: 329-333

22. Haghdoost S, Svoboda P, Naslund I, Harms-Ringdahl M, Tilikides A, et al (2010) Can 8-oxo-dG be used as a predictor for individual radiosensitivity? Int J Radiat Oncol Biol Phys 50: 405-410.

23. Paz-Elizur T, Ben-Yosef R, Elinger D, Vexler A, Krupsky M, et al. (2006 Reduced repair of the oxidative 8-oxoguanine DNA damage and risk of head and neck cancer. Cancer Res 66: 11683-11689.

24. Loft S, Høgh Danielsen P, Mikkelsen L, Risom L, Forchhammer L, et al. (2008) Biomarkers of oxidative damage to DNA and repair. Biochem Soc Trans 36 1071-1076.

25. Sasse AD, Clark LG, Sasse EC, Clark OA (2006) Amifostine reduces side effects and improves complete response rate during radiotherapy: results of a meta-analysis. Int J Radiat Oncol Biol Phys 64: 784-791.

26. Lawenda BD, Kelly KM, Ladas EJ, Sagar SM, Vickers A, et al. (2008) Should Supplemental Antioxidant Administration Be Avoided During Chemotherapy and Radiation Therapy? J Natl Cancer Inst 100: 773-783.

27. Strack D, Vogt T, Schliemann W (2003) Recent advances in betalain research Phytochemistry 62: 247-269.

28. Reddy MK, Alexander-Lindo RL, Nair MG (2005) Relative inhibition of lipid peroxidation, cyclooxygenase enzymes, and human tumor cell proliferation by natural food colors. J Agric Food Chem 53: 9268-9273.

29. Kapadia GJ, Tokuda H, Konoshima T, Nishino H (1996) Chemoprevention of lung and skin cancer by Beta vulgaris (beet) root extract. Cancer Lett 100 211-214.

30. Lee CH, Wettasinghe M, Bolling BW, Ji LL, Parkin KL (2005) Betalains, phase Il enzyme-inducing components from red beetroot (Beta vulgaris) extracts. Nutr Cancer 53: 91-103.

31. Bentzen SM (2006) Preventing or reducing late side effects of radiation therapy: radiobiology meets molecular pathology. Nature Rev Cancer 6: 702-723.

32. Barcellos-Hoff MH, Park C, Wright EG (2005) Radiation and the microenvironment - tumorigenesis and therapy. Nat Rev Cancer 5: 867-875. 